\title{
Research Progress of Denitrifying Dephosphatation in SBR System
}

\author{
Liang Shi ${ }^{1,}$, Liping Qiu ${ }^{1, b^{*}}$, Shoubin Zhang ${ }^{1, c}$, Jiabin Wang ${ }^{1, d}, K$ ang Xie ${ }^{1, e}$ \\ ${ }^{1}$ School of Civil Engineering and Architecture, University of Jinan, No.336. West Road of Nan \\ Xinzhuang. Jinan. 250022, PR China \\ ashinystone2015@163.com, ${ }^{b^{*}}$ cea_qiulp@ujn.edu.cn, ${ }^{c}$ cea_zhangsb@ujn.edu.cn, \\ 'cea_wangjb@ujn.edu.cn, ${ }^{\mathrm{e}}$ cea_xiek@ujn.edu.cn, \\ * Corresponding Author
}

\begin{abstract}
Keywords: SBR; Denitrifying Dephosphatation; Granular Sludge
Abstract. Recently, researches and applications of denitrifying and phosphorus accumulating organisms (DPAOs) in treating eutrophic water are becoming more and more extensive. Treatment technologies with DPAOs are SBR、 $\mathrm{A}^{2} \mathrm{O} 、 \mathrm{AO} 、 \mathrm{~A} / \mathrm{O} / \mathrm{A}$ etc. and they all have their own pros and cons, respectively. According to the latest research findings on denitrifying dephosphatation in SBR system, the mechanisms and operating effect are summarized. Researches of granular sludge in processes of denitrifying dephosphatation are also discussed to provide novel ideas for developing of conventional biological denitrification and phosphorus removal.
\end{abstract}

\section{Introduction}

The sequence batch reactor (SBR) process removes nitrogen and phosphorus in accordance with the time order, it has been applied widely owing to its flexibility in operation and management, resistance capacity on impact load and economy on investment of capital construction. Whereas, effluent of conventional SBR process could not meet the ascending standard on nitrogen and phosphorus release, therefore, modification on the process is imperative under the situation. In this paper, current domestic and international research findings on new-fashioned SBR process using DPAOs to achieve denitrifying dephosphatation are summarized, and thus provides new ideas for development of conventional biological denitrification and phosphorus removal.

\section{Mechanism of Denitrifying Dephosphatation}

Under anaerobic conditions, DPAOs can use proton motive force generated from the decomposition of phosphorus compounds to transport volatile fatty acid (VFA) such as propionate and acetate into cells via active transport, and then produce acetyl coenzyme A (AcCoA) under the action of acetyl coenzyme A synthetase, latter, AcCoA is transformed and stored in the form of PHA. During this conditions, propionate and acetate are stored as four kinds of PHAs after transormed, the major enxistence form are Poly - beta hydroxy butyric acid (PHB) and Polyhydroxyvalerate (PHV), among which the PHB is merely transformed from AcCoA, while PHV and its isomer Poly hydroxy -2- methyl butyrate $\left(\mathrm{PH}_{2} \mathrm{MB}\right)$ are transformed from AcCoA and propionyl coenzyme A (propiony-CoA), and Poly hydroxy -2- methyl valeric $\left(\mathrm{PH}_{2} \mathrm{MV}\right)$ is only transformed from propiony-CoA ${ }^{[1]}$. In this procedure, DPAOs utilize Adenosine Triphosphate (ATP) come from the decomposition of phosphorus compounds to provide enough energy for the synthsis of PHA, and reducing force needed for the synthsis is provided by the decomposition of glycogen.

The decomposition pathways of glycogen are mainly Embden-Meyerhof- Parnas pathway (EMP) and Entner-Doudoroff pathway (ED), but the former can produce more ATP. Metabolism differs between bacterial strains, Martín et $\mathrm{al}^{[2]}$ discovered genes needed for the EMP pathway and Tricarboxylic acid cycle (TCA) in A. phosphatis, but not for the ED pathway, which was first discovered by N. Entner and M.Doudoroff, that exists as an alternative pathway in those microorganisms lacking completed EMP pathaway. Besides, DPAOs can also produce dihydronicotinamide adenine dinucleotide $\left(\mathrm{NADH}_{2}\right)$ through TCA pathway to assist the synthsis of 
PHA owing to the discovery of Martín et al that a new type of genome encoding the cytochrome in $A$. phosphatis can allow the TCA pathway happen even uner anaerobic conditions. Pereria et al ${ }^{[3]}$ utilized ${ }^{13} \mathrm{C}$ atomic tracer labeling technology in their research and found that TCA cycle under anaerobic conditions can provide $30 \%$ reducing force for the synthsis of PHV.

Under aerobic conditions, DPAOs can use oxygen as electron acceptor and decompose PHA stored in the cells to produce AcCoA or Propiony-CoA which will latter participate the TCA pathway, thus create massive ATP, most of which is used for the growth and reproduction of microorganisms themself and for the synthsis of glycogen, the rest small part is for excessive adsorption of phosphate, and stored in the form of polyphosphate. In fact, most DPAOs are facultative anaerobes, they can also utilize nitrate or nitrite as electron acceptor under anoxic conditions, and with energy from the decomposition of ATP, they can maintain life activities and excessively absorb phosphate in the surrounding environment to synthetise polyphosphate, which wll be stored in the cells. In this procedure, the reduction of nitrogen and phosphorus removal process are organically combined.

The difference of DPAOs' metabolic mechanism under anrobic and anoxic conditions is that the last electron acceptor of electron-transport chain that produces energy are distinct, reaction equations are as follows (nitrate is used as electron acceptor under anoxic conditions):

Aerobic:

Anoxic:

$$
\mathrm{NADH}_{2}+0.5 \mathrm{O}_{2} \rightarrow \delta \mathrm{ATP}+\mathrm{H}_{2} \mathrm{O}
$$

$$
\mathrm{NADH}_{2}+0.4 \mathrm{HNO}_{3} \rightarrow \delta_{\mathrm{N}} \mathrm{ATP}+0.2 \mathrm{~N}_{2}+1.2 \mathrm{H}_{2} \mathrm{O}
$$

The $\delta$ and $\delta_{\mathrm{N}}$ in the equations are energy production efficiency $\left(\operatorname{molATP} / \mathrm{molNADH}_{2}\right)$ under aerobic and anoxic conditions respectively. Learn from the denitrifying dephosphatation models established separately by Kuba et al $^{[4]}$ and Smolders et al ${ }^{[5]}$, aerobic condition differs with anoxic condition in the productivity efficiency of ATP. Experiments tells us that under anoxic conditions, the $\delta_{\mathrm{N}}$ is about 1.0 mol ATP / mol $\mathrm{NADH}_{2}$, while $\delta_{\mathrm{N}}$ under aerobic is about $1.85 \mathrm{~mol} \mathrm{ATP} \mathrm{/} \mathrm{mol} \mathrm{NADH}_{2}$, thus we can know that when nitrate is used as electron acceptor, the ATP production is $40 \%$ lower than that when oxygen is used as electron acceptor, and this circumstance also leads to the fact that productivity ratio of DPAOs is $24 \%$ lower than PAOs ${ }^{[6]}$.

\section{The Denitrifying Dephosphatation process}

There are two different types of denitrifying dephosphatation process depending on whether DPAOs and nitrifying bacteria are in the same reactor, namely, single-sludge system and two-sludge system.

Two-sludge system. Wang et al ${ }^{[7]}$ combined anaerobic/anxic SBR $\left(\mathrm{A}_{2}-\mathrm{SBR}\right)$ and nitrifying SBR (N-SBR) into a two-sludge system, $\mathrm{A}_{2} \mathrm{~N}-\mathrm{SBR}$, to study denitrifying dephosphatation. Seeing from the reaction path, activated sludge in two reactors don't contact each other,but just exchange supernatant after sedimentation, which efficiently solves the contradiction that DPAOs have different generation period with nitrifying bacteria, thus, both microorganisms can better exert its processing efficiency.

The results demonstrated that better removal efficiency could be achieved even quality of system influent fluctuates largely or carbon/nitrogen ratio $(\mathrm{C} / \mathrm{N}$ ratio) of the influent is lower. Removal rates of chemical oxygen demand $\left(\mathrm{COD}_{\mathrm{cr}}\right)$, ammonia nitrogen $\left(\mathrm{NH}_{3}-\mathrm{N}\right)$, total nitrogen $(\mathrm{TN})$ and phosphorus $(\mathrm{P})$ in this system reached $85.89 \%, 82.3 \%, 88.99 \%$ and $84.56 \%$, respectively. When the carbon/phosphorus ratio ( $\mathrm{C} / \mathrm{P}$ ratio) is no less than 19.36 , better removal efficiency of $\mathrm{P}$ can be achieved, while it declines when $\mathrm{C} / \mathrm{P}$ ratio is under 15.36 . However, due to that $\mathrm{NH}_{3}-\mathrm{N}$ might be delayed in the reactor under anaerobic conditions, TN concentration of system effluent may be higher.

In order to solve this problem without disturb the good efficiency of denitrifying dephosphatation, LIU et al ${ }^{[8]}$ used granular sludge instead of traditional floc sludge in the $\mathrm{A}_{2} \mathrm{~N}-\mathrm{SBR}$ system, besides, a second aeration was adopted after the anoxic period in anaerobic/nitrifying/anoxic procedure, to further remove $\mathrm{P}$ and $\mathrm{NH}_{3}-\mathrm{N}$. In the steady period of the system, removal rate of $\mathrm{NH}_{3}-\mathrm{N}$ reached $94.5 \%$, specific ammonia oxidation rate is $0.10 \sim 0.25 \mathrm{mg} \cdot \mathrm{g}^{-1} \cdot \mathrm{min}^{-1}, \mathrm{NH}_{3}-\mathrm{N}$ concentration in the effluent is $7.76 \mathrm{mg} / \mathrm{L}$. While the $\mathrm{C} / \mathrm{N}$ ratio is 6.0 , removal rates of $\mathrm{P}$, nitrate $\left(\mathrm{NO}_{3}{ }^{-} \mathrm{N}\right)$ and nitrite $\left(\mathrm{NO}_{2}{ }^{-} \mathrm{N}\right)$ could reach $85 \%, 90.6 \%$ and $90.6 \%$, and $\mathrm{TN}$ concentration in the effluent was $10 \mathrm{mg} / \mathrm{L}$. It has to be noted that $\mathrm{COD}_{\text {cr }}$ concentration in the effluent was just $43.3 \mathrm{mg} / \mathrm{L}$ and the average removal rate was $78.8 \%$, 
with the $\mathrm{COD}_{\text {cr }}$ load reaching as high as $0.15 \sim 0.42 \mathrm{mg} / \mathrm{mg}$, which performance that ordinary single-sludge system can not reach. In addition, phosphate of high density released during anaerobic conditions can promote the growth of nitrifying bacteria, whereas, this situation can also come true in the single-sludge systetm created by Tsuneda et al ${ }^{[9]}$, but, extra canbon source is needed to restrain $\mathrm{P}$ adsorption in aerobic conditions for better $\mathrm{P}$ removal efficiency, which problem that would not be considered in two-sludge systems owing to that both sludge are independent with each other.

Single-sludge system. Wang et al ${ }^{[10]}$ succeeded in enriching DPAOs through adding anoxic periods in stage one's anaerobic/aerobic operation mode, namely, anaerobic/anoxic/aerobic/anoxic mode. Final removal rates of $\mathrm{COD}_{\mathrm{cr}}, \mathrm{P}$ and $\mathrm{TN}$ are $92 \%, 98 \%$ and $81.5 \%$, besides, $\mathrm{NO}_{2}^{-}-\mathrm{N}$ with the concentration of $30 \mathrm{mg} / \mathrm{L}$ was found less inhibiting to $\mathrm{P}$ adsorption in anoxic conditions, and they also found that ratio of P-uptake was higher when $\mathrm{NO}_{2}^{-}-\mathrm{N}$ was used as the only electron acceptor, rather than $\mathrm{NO}_{3}{ }^{-} \mathrm{N}$. However, extra carbon source should be dosed to the second anoxic period when stage two was running.

Ma et al ${ }^{[11]}$ utilized single-sludge system to treat synthsis waste water with operation anaerobic/aerobic/anoxic mode. It was found that $\mathrm{COD}_{\mathrm{cr}}$ in the system remained unchanged after the anaerobic period finished, which indicating organic matters has been removed effectively. It was also found that $\mathrm{P}$ concenration in the effluent fluctuate heavily, considering that $\mathrm{NH}_{3}-\mathrm{N}$ concentration in the influent changed largely, duration of $\mathrm{P}$ removal of denitrifying dephosphatation in the forepart of anoxic period could not be ascertained, when $\mathrm{NH}_{3}-\mathrm{N}$ concentration in the influent was very low, DPAOs could not fully play their roles during the latter part of anoxic period even all the ammonia was nitrified, and second release of $\mathrm{P}$ might happen in the relatively long anoxic period, while removal of $\mathrm{P}$ mainly depends on PAOs ${ }^{6}$ adsorption of $\mathrm{P}$ under aerobic conditions, thus leading to unsatisfactory efficiency of $\mathrm{P}$ removal. In order to estimate the end point of denitrification accurately, real-time control strategy was employed to monitor the characteristic points of $\mathrm{pH}$ curve during the denitrification process, which points can help estimate the end point and improve the stability of phosphorus removal in the system. Moreover, they also discovered that when dissolved oxygen (DO) in the forepart of aerobic period was lower than $1 \mathrm{mg} / \mathrm{L}$, accummulation of $\mathrm{NO}_{2}{ }^{-} \mathrm{N}$ happened, and till the end of the whole aerobic period, average accummulation came up to $2.86 \mathrm{mg} / \mathrm{L}$, however, $\mathrm{NO}_{2}{ }^{-} \mathrm{N}$ concentration at the end of anoxic period was less than $0.33 \mathrm{mg} / \mathrm{L}$, indicating that accummulation of $\mathrm{NO}_{2}^{-}-\mathrm{N}$ didn't restrain the denitrification, but served as electron acceptor and was reduced.

\section{The Granular Sludge}

The granular sludge was first found in anaerobic systems in 1980s, compared with traditional activated sludge, it has inerratic shape (mainly spherical or axiolitic), tight structure, massive biomass, good performance of sedimentation and strong resistance for impact load, with all this virtues, it has gotten the favour of many scholars at home and abroad.

Zhang et al ${ }^{[12]}$ studied the formation of denitrifying dephosphatation granular sludge under anaerobic/aerobic/anoxic mode of SBR process. The formation procedure was divided into three stages via controlling influent quality of the reactor and hydraulic retention time (HRT) of each phase during a whole cycle. In the first stage, flocculent sludge began to auto-agglutinate with the help of hydraulic shear force, in the later two phases, sludge's self-condensing capacity became stronger and stronger, small granules were formed, and they became more and bigger with time went on, finally, compact spherical or axiolitic granules were formed, with particle size range from $0.6 \mathrm{~mm}$ to $3.0 \mathrm{~mm}$, but most of the size are in $0.9 \sim 1.5 \mathrm{~mm}$, distribution of particle size obeys standard normal distribution.

Wang et al ${ }^{[13]}$ studied long-term impact of anaerobic reaction time on the performance and granular characteristics of granular denitrifying biological phosphorusremoval systems. The results demonstrates that the relatively long anaerobic retention time (AnRT) influenced the intracellular intermediate metabolites and activities of intracellular enzymes negatively, owing to encountering more frequent free nitrite acid (FNA) inhibition during the adaptation period, resulting in lower poly-P levels and activity of polyphosphate kinase (PPK). This provided a selective advantage for glycogenaccumulating organisms /denitrifying glycogen-accumulating organisms (GAOs/DGAOs) over PAOs/DPAOs, leading to deteriorated denitrifying PAOs performance. Additionally, more frequent 
encountering of either FNA inhibition or anaerobic endogenous respiration from the longest AnRT led to the highest extracelluar polymeric substances (EPS) production and the largest size of granules, which in turn reduced the rates of anaerobic PHA synthesis and glycogen degradation. Phosphorus removal capacity was mediated to some extent by EPS adsorption and chemical sedimentation in granular sludge systems that possessed more EPS and a longer AnRT, while relatively higher GAOs.

\section{Conclusion}

It is energy saving, green and effective by adopting SBR process to remove nutritional elements in waste water. Taking those virtues of granular sludge into consideration, more economical and more effective achievement could be realized if they can be combined into one process and applied to practical engineering applications, for which achievements we need further study on the denitrifying dephosphatation mechanism of granular sludge and ascertain the optimal culture conditions and control condition to achieve optimal treatment effects.

\section{Acknowledgements}

This study was partly supported by National Natural Science Foundation of China (51278225), Science and technology development projects of Shandong province (2013GSF11704), Shandong Provincial Natural Science Foundation (ZR2013EEQ007, ZR2015EM021), and Science and technology development projects of Jinan (201302079).

\section{References}

[1] S. He and K.D. McMahon: Microbial Biotechnology Vol.4 (2011), p. 603

[2] H. G. Martín, N. Ivanova, V. Kunin, F.et al: Nature Biology Vol. 24 (2006), p. 1263

[3] H. Perreira, P. C. Lemos, M. A. M. Reis, J. P. S. G. Crespo, M. J. T. Carrondo and H. Santos: Water Research Vol. 30 (1996), p. 2128

[4] T. Kuba, M. C. M. van. Loosdrecht and J. J. Heijnen: Biotechnol. Bioeng Vol. 52 (1996), p. 685

[5] G. J. F. Smolders, J. van. Der. Meij, M. C. M. van. Loosdrecht, et al: Biotechnol. Bioeng Vol. 43 (1994), p. 461

[6] Jian Chen: Food Biotechnology Vol. 21 (2002), p. 10. In Chinese.

[7] Yayi Wang, Yongzhen Peng and Fangfang Yin: Environment Science Vol. 29 (2008), p. 1526. In Chinese.

[8] Xu Liu, Shuying Wang and Yongzhen Peng: Acta Scientiae Circumstantiae Vol. 32 (2012), p.1537. In Chinese.

[9] S. Tsuneda, T. Ohno, K. Soejima, et al: Biochemical Engineering Journal Vol. 27 (2005), p. 191

[10] Jianlong Wang, Shuying Wang and Yongqing Gao: Journal of Beijing University of Technology Vol. 34 (2008), p. 179. In Chinese.

[11] Bin Ma, Yongzhen Peng and Guibing Zhu: Chinese water supply and drainage Vol. 25 (2009), p. 25. In Chinese.

[12] Xiaoxin Zhang, Shan Qiu, Jixian Yang et al: Chinese water supply and drainage Vol. 27 (2004), p. 85. In Chinese.

[13] Yayi Wang, Gang Guo, Hong Wang, et al: Water Research Vol. 47 (2013), p. 5326. In Chinese. 